\title{
Palladium\#Catalyzed
}

\section{Intermolecular Aryliodination of Internal Alkynes}

\section{Journal Article}

\section{Author(s):}

Lee, Yong Ho (1D; Morandi, Bill

Publication date:

2019-05-06

\section{Permanent link:}

https://doi.org/10.3929/ethz-b-000328093

Rights / license:

In Copyright - Non-Commercial Use Permitted

Originally published in:

Angewandte Chemie. International Edition 58(19), https://doi.org/10.1002/anie.201812396

Funding acknowledgement:

757608 - Shuttle Catalysis for Reversible Molecular Construction (EC) 


\title{
Palladium-Catalyzed Intermolecular Aryliodination of Internal
} Alkynes

\author{
Yong Ho Lee ${ }^{[a, b]}$ and Bill Morandi ${ }^{*[a, b]}$ \\ Dedication ((optional))
}

\begin{abstract}
A completely atom economical palladium-catalyzed addition reaction has been developed to stereoselectively access functionalized tetrasubstituted alkenyl iodides. The palladium catalyst bearing an electron-poor bidentate ligand rarely employed in catalysis, is essential to promote the high yielding and chemoselective intermolecular reaction between equimolar amounts of an alkyne and an aryl iodide. This new carbohalogenation reaction is an attractive alternative to traditional synthetic methods, which rely on multi-step synthetic sequences and protecting group manipulations.
\end{abstract}

Atom economy is a critical aspect in the development of novel organic reactions. ${ }^{[1]}$ Accordingly, hydrofunctionalizations of either alkenes or alkynes have been extensively studied both industrially and academically (Scheme 1a)..$^{[2-4]}$ In contrast, efficient difunctionalization reactions to add two distinct functional groups across an alkene or alkyne are scarce, despite their great synthetic potential (Scheme 1b). ${ }^{[5-13]}$ Most notable examples include $\mathrm{C}-\mathrm{CN},{ }^{[5]} \mathrm{C}-\mathrm{SR},{ }^{[7]}$ and decarbonylative C-COCI ${ }^{[8 c]}$ addition across alkynes.

The synthesis of alkenyl halides from easily accessible compounds is an important goal, ${ }^{[14]}$ since these compounds are ideal substrates in many transition metal catalyzed coupling reactions. ${ }^{[15]}$ Tetrasubstituted alkenyl halides, despite their synthetic utility, cannot be accessed by simple addition reaction between aryl or acyl halides and internal alkynes. ${ }^{[4 c-d, 8]}$ Instead, traditional methods require multi-step synthesis, employ stoichiometric amounts of reactive organometallic reagents, and have limited functional group tolerance (Scheme 1c). ${ }^{[15 c, 16]}$ Alternatively, multi-component synthetic routes to access tetrasubstituted alkenes have been reported using the direct coupling of in situ generated alkenyl-M-X ( $M=M g$ or $\mathrm{Pd}, \mathrm{X}=\mathrm{Br}$ or I) with corresponding coupling partners such as aryl-Ni(II) complexes or aryl boronic acids, respectively. ${ }^{[17]}$ These methods are limited in scope and in the diversity of accessible scaffolds. Alternative radical strategies suffer from rapid $E / Z$ isomerization due to intrinsic instability of alkenyl radical intermediates. ${ }^{[3,10,18]}$ In theory, a simple addition between broadly available aryl halides and alkynes would be the most versatile route to alkenyl halides (Scheme 1d). Lautens and co-workers have pioneered this area through the development of several multiple bonds carboiodination reactions. ${ }^{[11-13]}$ However, the reactions between aryl halides and alkynes have so far been restricted to intramolecular cyclization processes using a limited scope of alkyne tethers, ${ }^{[11]}$ or to processes that need to be terminated by a second addition reaction of the alkenyl-Pd-I intermediates onto a neighboring alkene moiety. ${ }^{[12]} \mathrm{A}$ notable exception was reported during the preparation of this manuscript, where a non stereoselective $\mathrm{Ni}$-catalyzed alkyne aryliodination reaction involving radical intermediates was disclosed. ${ }^{[19]}$ These features highlight the challenges in achieving a simple addition reaction that proceeds through direct reductive elimination of a alkenyl iodide. ${ }^{[20]}$ Here, we report a Pd-catalyzed intermolecular reaction between a broad range of aryl iodides and internal alkynes to stereoselectively access alkenyl iodides. Following our recent studies on catalytic functional group metathesis,,21-22] we envisaged that a Pd catalyst and a suitable ligand would be an appropriate platform for the development of an intermolecular carboiodination reaction (Scheme 1d). However, the putative Pdalkenyl intermediate resulting from the oxidative addition of aryl iodide and alkyne insertion could participate in undesired oligomerization through subsequent iterative alkyne insertion. ${ }^{[17 a, 23]}$

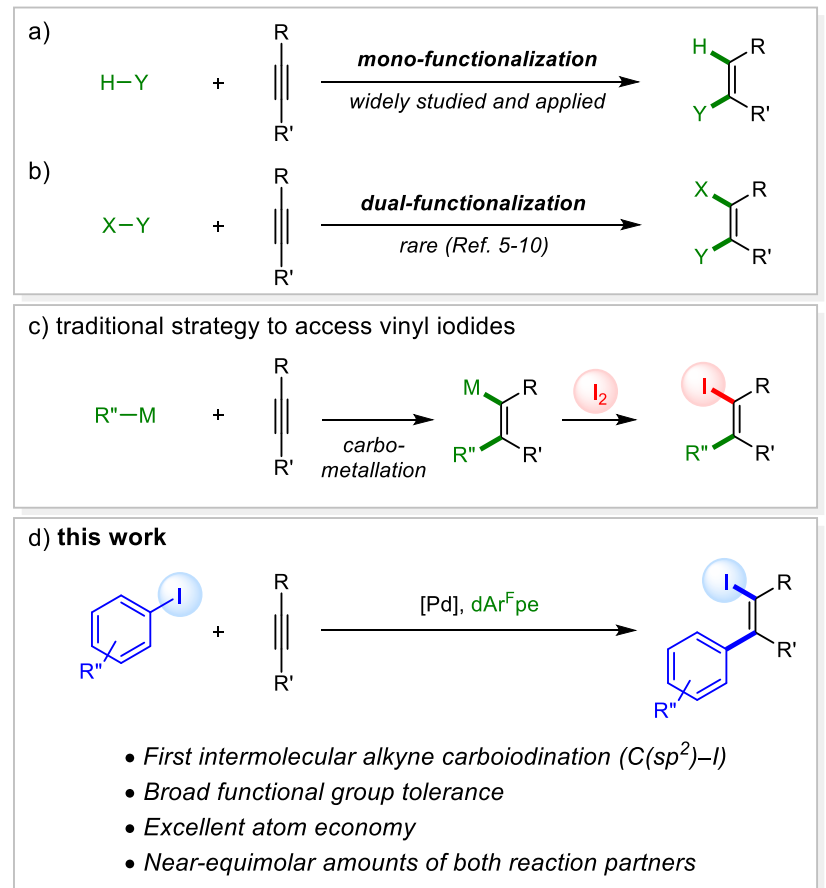

Scheme 1. Context of the Work. [a] Y. H. Lee, Prof. Dr. B. Morandi

Max-Planck-Institut für Kohlenforschung

Kaiser-Wilhelm-Platz 1, 45470 Mülheim an der Ruhr, Germany

[b] Y. H. Lee, Prof. Dr. B. Morandi

Laboratorium für Organische Chemie

ETH Zürich

Vladimir-Prelog-Weg 3, $\mathrm{HCl}, 8093$ Zürich, Switzerland

E-mail: bill.morandi@org.chem.ethz.ch

Supporting information for this article is given via a link at the end of the document. 


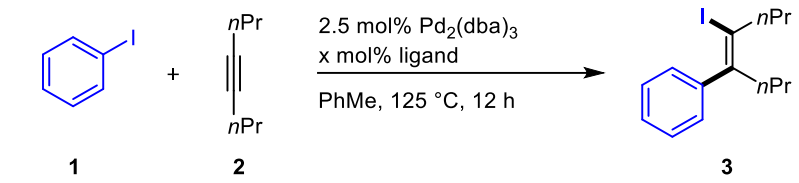

\begin{tabular}{ccccc}
\hline entry & ligand & $x(\mathrm{~mol} \%)$ & yield $(\%)^{[\mathrm{b}]}$ & Z/E selectivity \\
\hline 1 & L01 & 5 & 7 & $65 / 35^{[\mathrm{c}]}$ \\
2 & L01 & 10 & 64 & $59 / 41^{[\mathrm{c}]}$ \\
3 & L01 & 15 & $84(79)$ & $46 / 54^{[\mathrm{d}]}$ \\
4 & L02 & 5 & 10 & $>99 / 1^{[\mathrm{d}]}$ \\
5 & L02 & 10 & 73 & $>99 / 1^{[\mathrm{d}]}$ \\
6 & L02 & 15 & $82(78)$ & $>99 / 1^{[\mathrm{d}]}$ \\
7 & L03-L05 & 15 & $<1$ & - \\
8 & L06-L09 & 30 & $<1$ & - \\
\hline
\end{tabular}

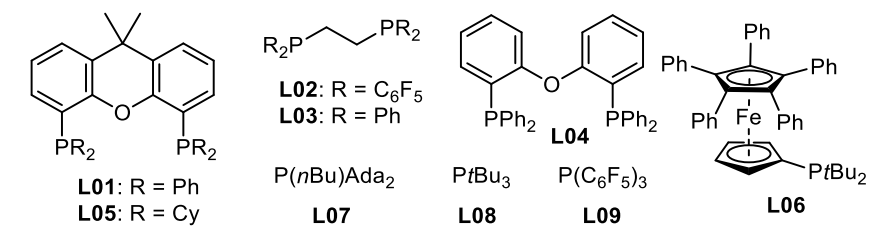

[a] 1 (0.25 mmol), 2 (1 equiv.), $\mathrm{Pd}_{2}(\mathrm{dba})_{3}(2.5 \mathrm{~mol} \%)$, toluene, $125^{\circ} \mathrm{C}, 12 \mathrm{~h}$. [b] $\mathrm{GC}$ yields; isolated yields given in parentheses. Selectivities determined by GC analysis ${ }^{[\mathrm{c}]}$ and by ${ }^{1} \mathrm{H}$ NMR. ${ }^{[\mathrm{d}]}$

We initially explored the possibility of transforming a simple internal alkyne into the corresponding alkenyl iodide using Xantphos (L01) as a ligand (Table 1). The catalytic Pd system resulted in low but unambiguous conversion to the desired products as a mixture of stereoisomers. This result is likely attributed to the high stability of the $\mathrm{Pd}(\mathrm{II})$ intermediates generated from oxidative addition, which prevents the regeneration of the active $\operatorname{Pd}(0)$ species. Inspired by Hartwig's seminal work which has shown that the rate of reductive elimination has a linear dependence on the concentration of a phosphine ligand, ${ }^{[24]}$ we could increase the yield to $84 \%$ when additional ligand was employed. Various other ligands including Xantphos analogues resulted in low conversion. In contrast, dArFpe (L02), which is rarely employed in $\mathrm{Pd}$-catalysis, ${ }^{[25]}$ led to a very active and selective catalyst for the desired transformation $(82 \%$ yield, Z/E $>99 / 1$ ). We surmise that the use of an excess of a ligand that is both electron deficient and bidentate is key to favor the reductive elimination step. The configuration of alkenyl iodides was determined by NOESY NMR analysis and X-ray crystallography. No excess of either of the reaction partners is required for this transformation. While the potential of electron withdrawing ligands to facilitate reductive elimination has been noted in the literature, ${ }^{[24 b, 26]}$ the vast majority of successful examples of C-I bond reductive elimination have described the use of electronrich, sterically hindered ligands. ${ }^{[20]}$ A rare exception to this is the result reported by Arndtsen and co-workers, in which they proposed that the presence of $\mathrm{CO}$ as a ligand on the $\mathrm{Pd}(\mathrm{II})$ center is crucial to the reductive elimination of extremely reactive aroyl triflate products. ${ }^{[27]}$

We next explored the scope of aryl iodides in this transformation using $\mathrm{dAr} F$ pe as a ligand and $\mathrm{Pd}_{2}(\mathrm{dba})_{3}$ and $\left[(\text { allyl)PdCl }]_{2}\right.$ as Pd sources (Table 2). A large range of substituted aryl iodides worked well under these conditions when either electron-rich or -deficient functional groups were present. A wide range of sterically encumbered ortho-substituted aryl iodides (47, 23-29) were also tolerated in this process. Using this catalytic reaction, several electron-rich functional groups, such as mono $(24,30,35)$, di (8), and trialkoxy (9), thiomethoxy (36), tertiary amine $(12,37)$ and alkyl $(4,26,38)$ substituents gave the corresponding products in high yields. Electron-poor aryl iodides also afforded excellent stereoselectivities and yields in this transformation, as illustrated by the tolerance of nitro (42), cyano (43), bis(trifluoromethyl) $(\mathbf{1 1})$, fluoro $(5,6,10,27)$, esters $(33,44)$, ketone (45) and even aldehyde (46), and azo (15) groups. The reaction could also be used to react the more electrophilic iodide site exclusively, with other less reactive (pseudo)halogens, such as chlorides $(\mathbf{2 0}, \mathbf{2 8}, 39)$, bromides $(\mathbf{1 9}, \mathbf{3 1}, \mathbf{3 2}, \mathbf{4 0})$ and triflate (41) remaining intact. Even an aryl boronic acid (52) that can engage in Suzuki-type couplings survived the conditions. A range of electron-rich and electron-poor heterocycles $(13,14,17-23)$ can serve as good substrates in the transformation. However, the use of heterocycles without any proximal substituent to hinder the plausible coordination of heteroatom to a metal center resulted in low conversions. Protic functionalities such as an alcohol (47), a carboxylic acid (48), an indole (13) and amides $(49,50)$ were tolerated to give moderate yields. This result is noteworthy in light of the limitation of traditional methods which require protection of such functionalities. This high functional group tolerance can be rationalized by the high chemoselectivity of Pd-catalyzed reactions under mild and neutral reaction conditions, particularly in the absence of a strong base or anionic organometallic species. ${ }^{[15]}$ Alkyl, alkenyl, alkynyl and allylic iodides were mostly unreactive under the present reaction conditions, a result that further highlights the high chemoselectivity of this catalytic system (see SI, Figure S3). Various symmetrical internal alkynes were reacted smoothly with aryl iodides (Table 3 ). We successfully performed a late-stage functionalization of three structurally different compounds derived from a chiral catalyst precursor (58), ${ }^{[28]}$ a natural product (estrone, 59) and a pharmaceutical intermediate $(60)$ (Table 3).

Next, we focused on the scope of unsymmetrical internal alkynes (Table 4). A steric variation of the alkynes gave a mixture of regioisomers with small but non-negligible differences in regioselectivity. The observed selectivity apparently arises from preferential aryl insertion at the distal position relative to the bulky group. This is consistent with literature examples of unsymmetrical alkyne hydrofunctionalization, where the regiochemistry is often controlled by steric effects in the absence of strong differences in electronics. ${ }^{[4 d, 5,23 a, 29]}$ However, in our case, the small difference in size between the aryl moiety and the $\mathrm{Pd}$ center does not seem to be significant enough to obtain high regioselectivities. In line with this hypothesis, two sterically hindered aryl iodides $(68,69)$ resulted in improved regioselectivities. An aryl iodide bearing a tethered alkyne group in its ortho position gave a selective intramolecular 6-exo-dig cyclic addition product (70). Terminal alkynes, such as 1-octyne and phenylacetylene, failed to give the desired products due to the formation of either oligomers or Sonogashira-type coupling side products. 

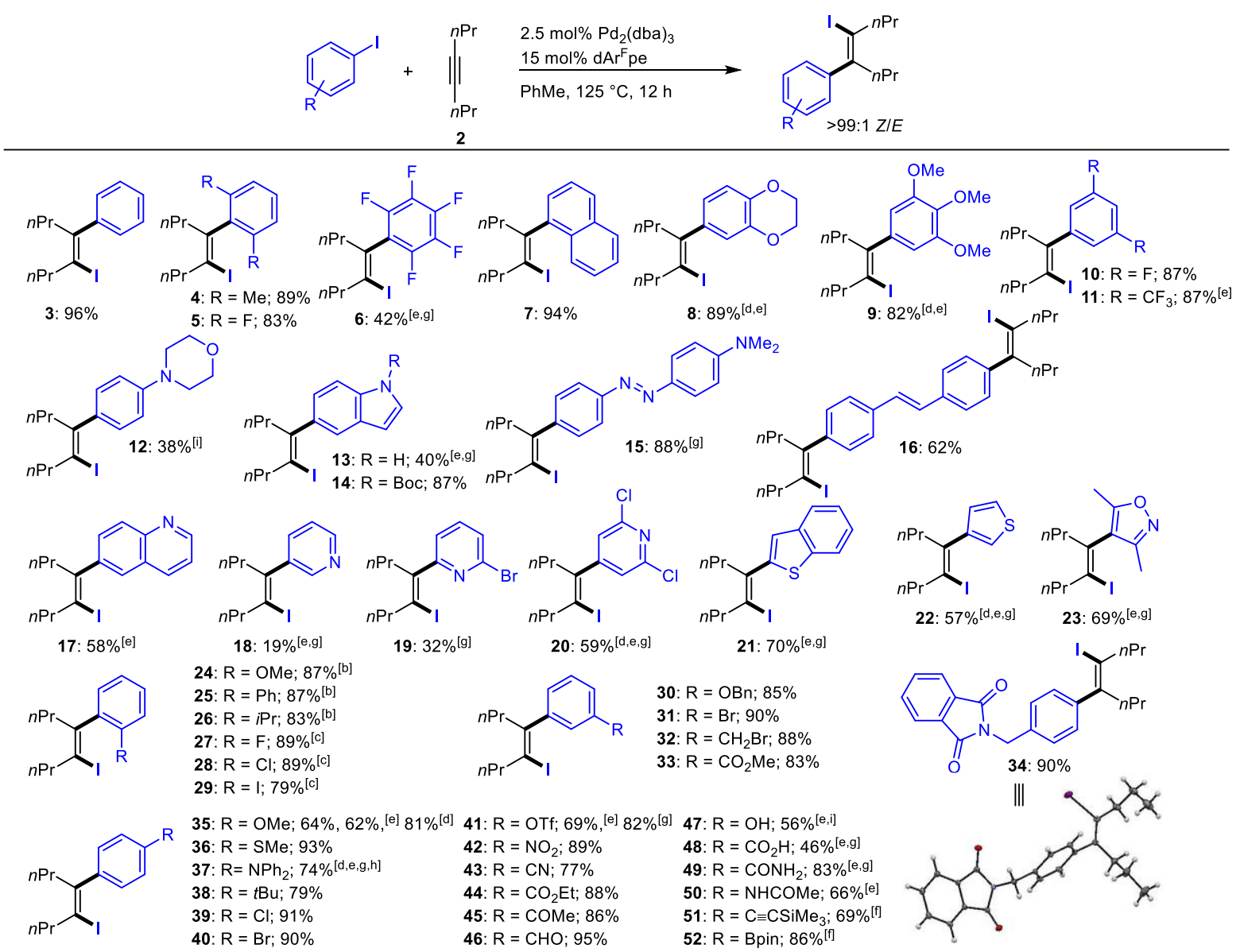

[a] Isolated yields (\%). Aryl iodide (0.25 mmol), alkyne (1.5 equiv.), $\mathrm{Pd}_{2}(\mathrm{dba})_{3}(2.5 \mathrm{~mol} \%), \mathrm{dArFpe}(15 \mathrm{~mol} \%)$, toluene, $125{ }^{\circ} \mathrm{C}, 12 \mathrm{~h}$. [b] 2 (1 equiv.). [c] 2 (1.2 equiv.). [d] 2 (3 equiv.). [e] o-xylene, $150^{\circ} \mathrm{C}$. [f] $100^{\circ} \mathrm{C}$. [g] $\mathrm{Pd}_{2}(\mathrm{dba})_{3}(5 \mathrm{~mol} \%), \mathrm{dAr}^{\mathrm{F} p e}(25 \mathrm{~mol} \%)$. [h] $24 \mathrm{~h}$. [i] [(allyl)PdCl] 2 (5 mol\%), dArFpe (25 mol\%).

Table 3. Scope of Symmetrical Internal Alkynes and Late-Stage Functionalization. ${ }^{[a]}$

$$
\text { PhMe, } 125^{\circ} \mathrm{C}, 12 \mathrm{~h}
$$

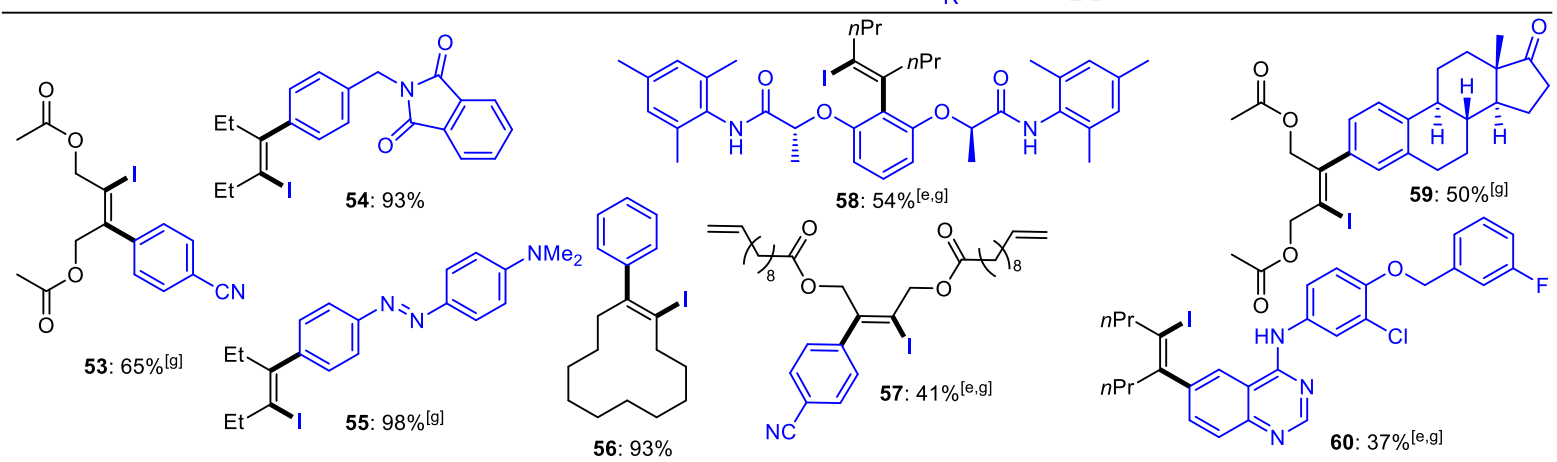

[a] Isolated yields (\%). For conditions see Table 2. 
Table 4. Scope of Unsymmetrical Internal Alkynes. ${ }^{[a]}$

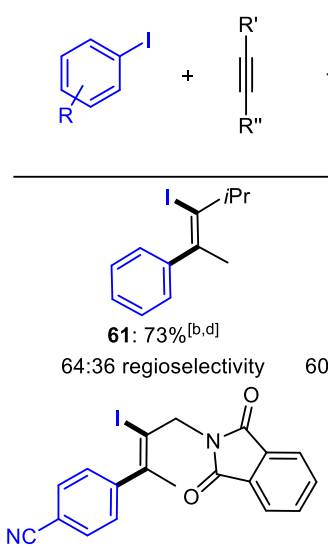

64: $68 \%{ }^{[\mathrm{b}, \mathrm{d}]}$

63:37 regioselectivity

\section{$2.5 \mathrm{~mol} \% \mathrm{Pd}_{2}(\mathrm{dba})_{3}$ $15 \mathrm{~mol} \% \mathrm{dAr}^{\mathrm{p} e}$ \\ PhMe, $125^{\circ} \mathrm{C}, 12 \mathrm{~h}$}<smiles>CC/C(I)=C(/C)c1ccccc1</smiles>

62: $62 \%[$ [b,d] 0:40 regioselectivity

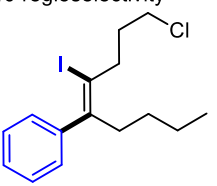

65: $82 \%[b, d]$

59:41 regioselectivity
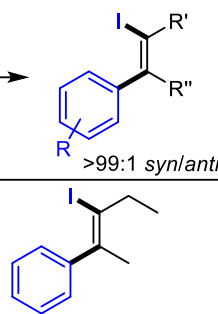

63: $63 \%[\mathrm{~d}]$ $57: 43$ regioselectivity

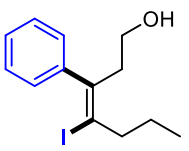

66: $39 \%{ }^{[b]}$<smiles>CCOCC(=C(I)CC)c1ccccc1</smiles>

67: $58 \%{ }^{[\mathrm{b}]}$

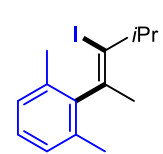

68: $75 \%[b, d]$

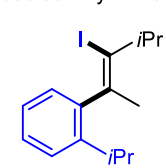

69: $82 \%[\mathrm{~b}, \mathrm{~d}]$
$60: 40$ regioselectivity $77: 23$ regioselectivity 68.32 regioselectivity

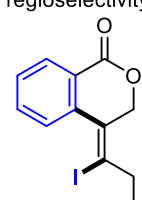

70: $52 \%[c]$

[a] Isolated yields (\%). For conditions see Table 2. [b] $\mathrm{Pd}_{2}(\mathrm{dba})_{3}(5 \mathrm{~mol} \%)$ dArFpe (25 mol\%). [c] [(allyl)PdCl]2 $(2.5 \mathrm{~mol} \%)$. [d] Isolated as an inseparable mixture of regioisomers.

Table 5. Scope of Silyl Alkynes. ${ }^{[a]}$

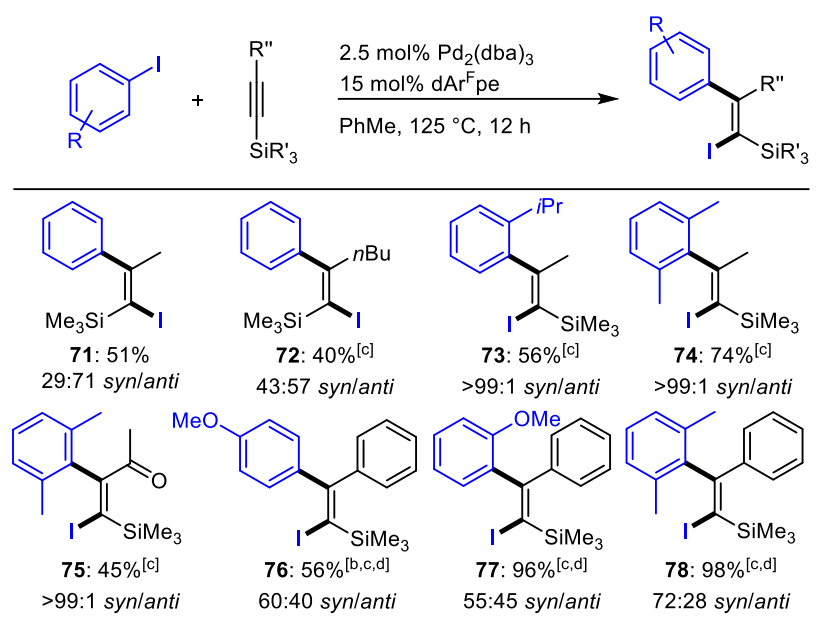

[a] Isolated yields (\%). For conditions see Table 2. [b] alkyne (3 equiv.). [c] $\mathrm{Pd}_{2}(\mathrm{dba})_{3}(5 \mathrm{~mol} \%), \mathrm{dAr}^{\mathrm{F}}$ pe $(25 \mathrm{~mol} \%)$. [d] Isolated as an inseparable mixture of stereoisomers.

While a number of alkyl and aryl silyl alkynes undergo efficient coupling with aryl iodides with complete regioselectivity, the reaction led to a mixture of $E / Z$ isomers (Table 5 ). The stereo- and regioselectivity is consistent with the intrinsic configurational instability of Si-substituted alkenes and regioselective preferences during other previously reported carbometallations. ${ }^{[16 \mathrm{~d}, 30]}$ Employing sterically crowded aryl iodides (73-75), the reactions result in exclusive syn addition and

regiospecific product formation. Alkenyl silanes can easily be transformed through subsequent desilylation, oxidation and ipsosubstitution of the silyl group. ${ }^{[31]}$

In conclusion, we have reported the first intermolecular $\mathrm{Pd}$ catalyzed carboiodination reaction of alkynes involving the reductive elimination of a $\mathrm{C}\left(s p^{2}\right)$-iodine bond to give synthetically versatile alkenyl iodides. The use of an excess of dArFpe ligand relative to $\mathrm{Pd}$ was critical to promote the addition reaction, a strategy that proved effective in addressing this longstanding challenge in carbohalogenation chemistry. An unusually broad palette of diverse functional groups was tolerated and the resulting alkenyl iodides were stereoselectively obtained in good to excellent yields.

\section{Acknowledgements}

We acknowledge the Max-Planck-Society, the ERC (ShuttleCat, Project ID: 757608), ETH Zürich and LG Chem (fellowship to Y.H.L.). We thank B. List for sharing analytical equipment, and the NMR, MS and X-ray departments of the MPI für Kohlenforschung for technical assistance.

Keywords: carbohalogenation $•$ aryliodination $•$ alkenyl iodides $•$ palladium $\cdot$ catalysis

[1] a) Modern Alkyne Chemistry: Catalytic and Atom-Economic Transformations (Eds.: B. M. Trost, C.-J. Li), Wiley-VCH, Weinheim, 2015; b) B. M. Trost, Acc. Chem. Res. 2002, 35, 695-705.

[2] a) Transition Metals for Organic Synthesis (Eds.: M. Beller, C. Bolm), Wiley-VCH, Weinheim, 2004; b) F. Alonso, I. P. Beletskaya, M. Yus, Chem. Rev. 2004, 104, 3079-3159; c) X. Zeng, Chem. Rev. 2013, 113 , 6864-6900; d) T. Kitamura, Eur. J. Org. Chem. 2009, 1111-1125; e) V. M. Dong, K. G. M. Kou, D. N. Le, in Organic Reactions, Vol. 96 (Eds.: S E. Denmark et al.), Wiley, Hoboken, 2018, pp. 231-592.

[3] a) N. A. Till, R. T. Smith, D. W. C. MacMillan, J. Am. Chem. Soc. 2018 140, 5701-5705; b) H.-P. Deng, X.-Z. Fan, Z.-H. Chen, Q.-H. Xu, J. Wu, J. Am. Chem. Soc. 2017, 139, 13579-13584.

[4] a) S. Dérien, H. Klein, C. Bruneau, Angew. Chem. Int. Ed. 2015, 54, 12112-12115; b) J. Derosa, A. L. Cantu, M. N. Boulous, M. L. O’Duill, J L. Turnbull, Z. Liu, D. M. De La Torre, K. M. Engle, J. Am. Chem. Soc. 2017, 139, 5183-5193; c) D. A. Petrone, I. Franzoni, J. Ye, J. F. Rodríguez, A. I. Poblador-Bahamonde, M. Lautens, J. Am. Chem. Soc 2017, 139, 3546-3557; d) X. Fang, B. Cacherat, B. Morandi, Nat. Chem. 2017, 9, 1105-1109.

[5] a) Y. Nakao, S. Oda, T. Hiyama, J. Am. Chem. Soc. 2004, 126, 13904 13905; b) A. Yada, S. Ebata, H. Idei, D. Zhang, Y. Nakao, T. Hiyama Bull. Chem. Soc. Jpn. 2010, 83, 1170-1184; c) Y. Minami, H. Yoshiyasu, Y. Nakao, T. Hiyama, Angew. Chem. Int. Ed. 2013, 52, 883-887; d) H. Ren, G.-F. Du, B. Zhu, G.-C. Yang, L.-S. Yao, W. Guan, Z.-M. Su, Organometallics 2018, 37, 2594-2601; e) Y. Nakao, T. Hiyama, Pure Appl. Chem. 2008, 80, 1097-1107.

[6] M. Murakami, S. Ashida, T. Matsuda, J. Am. Chem. Soc. 2005, 127, 6932-6933.

[7] a) J. F. Hooper, A. B. Chaplin, C. González-Rodríguez, A. L. Thompson, A. S. Weller, M. C. Willis, J. Am. Chem. Soc. 2012, 134, 2906-2909; b) T. Shibata, A. Mitake, Y. Akiyama, K. S. Kanyiva, Chem. Commun. 2017 53,9016-9019; c) P. Ren, S. D. Pike, I. Pernik, A. S. Weller, M. C. Willis, Organometallics 2015, 34, 711-723; d) M. Iwasaki, N. Topolovčan, H. $\mathrm{Hu}, \mathrm{Y}$. Nishimura, G. Gagnot, R. Na nakorn, R. Yuvacharaskul, K. Nakajima, Y. Nishihara, Org. Lett. 2016, 18, 1642-1645.

[8] a) T. Iwai, T. Fujihara, J. Terao, Y. Tsuji, J. Am. Chem. Soc. 2009, 131 6668-6669; b) T. Iwai, T. Fujihara, J. Terao, Y. Tsuji, J. Am. Chem. Soc 2012, 134, 1268-1274; c) K. Kokubo, K. Matsumasa, M. Miura, M. Nomura, J. Org. Chem. 1996, 61, 6941-6946; d) T. Kashiwabara, K Fuse, R. Hua, M. Tanaka, Org. Lett. 2008, 10, 5469-5472; e) T. Kashiwabara, K. Kataoka, R. Hua, S. Shimada, M. Tanaka, Org. Lett. 2005, 7, 2241-2244; f) T. Kashiwabara, M. Tanaka, Adv. Synth. Catal. 2011, 353, 1485-1490.

[9] T. R. Hoye, J. Wang, J. Am. Chem. Soc. 2005, 127, 6950-6951.

[10] a) T. Xu, C. W. Cheung, X. Hu, Angew. Chem. Int. Ed. 2014, 53, 49104914; b) W. Deng, Y. Li, Y.-G. Li, H. Bao, Synthesis 2018, 50, 2974 2980 ; c) D. Xu, R. Rios, F. Ba, D. Ma, G. Gu, A. Ding, Y. Kuang, H. Guo, 
Asian J. Org. Chem. 2016, 5, 981-985; d) Y. Ichinose, S. Matsunaga, K Fugami, K. Oshima, K. Utimoto, Tetrahedron Lett. 1989, 30, 3155-3158.

[11] a) C. M. Le, P. J. C. Menzies, D. A. Petrone, M. Lautens, Angew. Chem Int. Ed. 2015, 54, 254-257; b) C. M. Le, X. Hou, T. Sperger, F. Schoenebeck, M. Lautens, Angew. Chem. Int. Ed. 2015, 54, 1589715900.

[12] a) X. Jia, D. A. Petrone, M. Lautens, Angew. Chem. Int. Ed. 2012, 51 9870-9872; b) B. M. Monks, S. P. Cook, Angew. Chem. Int. Ed. 2013, 52, 14214-14218.

[13] a) D. A. Petrone, M. Lischka, M. Lautens, Angew. Chem. Int. Ed. 2013 52, 10635-10638; b) Y. Lan, P. Liu, S. G. Newman, M. Lautens, K. N. Houk, Chem. Sci. 2012, 3, 1987-1995; c) S. G. Newman, M. Lautens, J. Am. Chem. Soc. 2011, 133, 1778-1780; d) S. G. Newman, J. K. Howell, N. Nicolaus, M. Lautens, J. Am. Chem. Soc. 2011, 133, 14916-14919 e) H. Yoon, A. D. Marchese, M. Lautens, J. Am. Chem. Soc. 2018, 140 10950-10954; f) H. Liu, C. Li, D. Qiu, X. Tong, J. Am. Chem. Soc. 2011 133, 6187-6193; g) H. Liu, C. Chen, L. Wang, X. Tong, Org. Lett. 2011 13, 5072-5075.

[14] M. J. Koh, T. T. Nguyen, H. Zhang, R. R. Schrock, A. H. Hoveyda, Nature 2016, 531, 459-465

[15] a) K. C. Nicolaou, P. G. Bulger, D. Sarlah, Angew. Chem. Int. Ed. 2005 44, 4442-4489; b) C. C. C. Johansson Seechurn, M. O. Kitching, T. J. Colacot, V. Snieckus, Angew. Chem., Int. Ed. 2012, 51, 5062-5085; c) A. B. Flynn, W. W. Ogilvie, Chem. Rev. 2007, 107, 4698-4745.

[16] a) M. Corpet, C. Gosmini, Chem. Commun. 2012, 48, 11561-11563; b) K. Murakami, H. Ohmiya, H. Yorimitsu, K. Oshima, Org. Lett. 2007, 9, 1569-1571; c) K. Murakami, H. Yorimitsu, K. Oshima, Org. Lett. 2009 11, 2373-2375; d) J.-N. Schäckermann, T. Lindel, Org. Lett. 2017, 19, 2306-2309; e) T. Stüdemann, M. Ibrahim-Ouali, P. Knochel, Tetrahedron 1998, 54, 1299-1316; f) G. Wang, E. Negishi, Eur. J. Org Chem. 2009, 1679-1682; g) S. Ma,; E. Negishi, J. Org. Chem. 1997, 62 784-785.

[17] a) F. Xue, J. Zhao, T. S. A. Hor, T. Hayashi, J. Am. Chem. Soc. 2015 137, 3189-3192; b) C. Zhou, R. C. Larock, J. Org. Chem. 2005, 70 3765-3777; c) C. Zhou, D. E. Emrich, R. C. Larock, Org. Lett. 2003, 5
1579-1582; d) X. Zhang, R. C. Larock, Org. Lett. 2003, 5, 2993-2996; e) B. M. Monks, S. P Cook J. Am Chem Soc 2012, 134, 15297-15300.

[18] a) P. S. Skell, R. G. Allen, J. Am. Chem. Soc. 1964, 86, 1559-1560; b) R. W. Fessenden, R. H. Schuler, J. Chem. Phys. 1963, 39, 2147-2195.

[19] T. Takahashi, D. Kuroda, T. Kuwano, Y. Yoshida, T. Kurahashi, S Matsubara, Chem. Commun. 2018, 54, 12750-12753.

[20] D. A. Petrone, J. Ye, M. Lautens, Chem. Rev. 2016, 116, 8003-8104

[21] Y. H. Lee, B. Morandi, Nat. Chem. 2018, 10, 1016-1022.

[22] M. De La Higuera Macias, B. A. Arndtsen, J. Am. Chem. Soc. 2018, 140 10140-10144

[23] a) Y. Nakao, K. S. Kanyiva, T. Hiyama, J. Am. Chem. Soc. 2008, 130, 2448-2449; b) J. Oyamada, T. Kitamura, Chem. Commun. 2008, 4992 4994.

[24] a) A. H. Roy, J. F. Hartwig, J. Am. Chem. Soc. 2003, 125, 13944-13945 b) A. H. Roy, J. F. Hartwig, Organometallics 2004, 23, 1533-1541.

[25] a) R. L. Cook, J. G. Morse, Inorg. Chem. 1982, 21, 4103-4105; b) H. Nakamura, T. Kamakura, S. Onagi, Org. Lett. 2006, 8, 2095-2098.

[26] J. F. Hartwig, Inorg. Chem. 2007, 46, 1936-1947.

[27] a) R. G. Kinney, J. Tjutrins, G. M. Torres, N. J. Liu, O. Kulkarni, B. A Arndtsen, Nat. Chem. 2018, 10, 193-199; b) Y. H. Lee, B. Morandi, Nat. Chem. 2018, 10, 116-117.

[28] S. Haubenreisser, T. H. Wöste, C. Martínez, K. Ishihara, K. Muñiz Angew. Chem. Int. Ed. 2016, 55, 413-417.

[29] a) N. Tsukada, T. Mitsuboshi, H. Setoguchi, Y. Inoue, J. Am. Chem. Soc 2003, 125, 12102-12103; b) Y. Nakao, K. S. Kanyiva, S. Oda, T. Hiyama J. Am. Chem. Soc. 2006, 128, 8146-8147; c) D. J. Schipper, M. Hutchinson, K. Fagnou, J. Am. Chem. Soc. 2010, 132, 6910-6911.

[30] a) B. B. Snider, M. Karras, J. Organomet. Chem. 1979, 179, C37-C41; b) B. B. Snider, M. Karras, R. S. E. Conn, J. Am. Chem. Soc. 1978 100, 4624-4626; c) M. Obayashi, K. Utimoto, H. Nozaki, J. Organomet. Chem. 1979, 177, 145-152.

[31] a) M. J. Curtis-Long, Y. Aye, Chem. Eur. J. 2009, 15, 5402-5416; b) E. Langkopf, D. Schinzer, Chem. Rev. 1995, 95, 1375-1408. 


\section{Authors' final submitted copy after peer review}

\section{Entry for the Table of Contents}

Layout 2:

\section{COMMUNICATION}

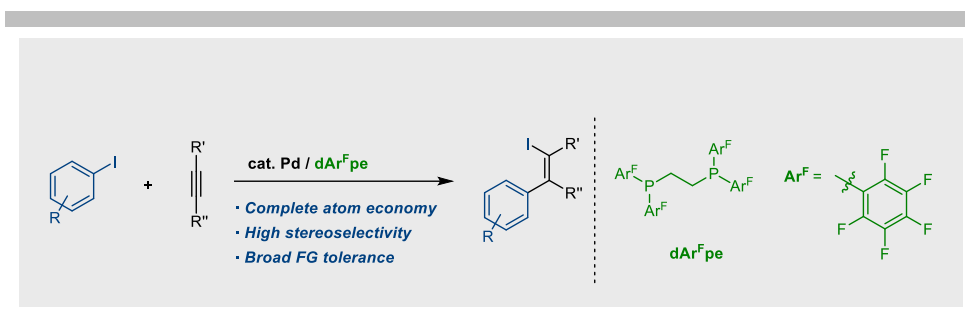

Yong Ho Lee and Bill Morandi*

A completely atom economical palladium-catalyzed addition reaction has been developed to stereoselectively access tetrasubstituted alkenyl iodides. The palladium catalyst bearing 1,2-bis[bis(pentafluorophenyl)phosphino]ethane ( $\mathrm{dArF}$ pe), an electron poor and bidentate ligand, is essential to promote the high yielding and chemoselective reaction between an alkyne and an aryl iodide.

Page No. - Page No.

Palladium-Catalyzed Intermolecular Aryliodination of Internal Alkynes 